\title{
Grouting of Waste of the Baikal Pulp and Paper Mill to Reduce the Technogenic Impact to the Baikal Lake Ecosystem
}

\author{
Eugene N. Samarin, Nataliia S. Kravchenko, Oleg V. Zerkal, Michael S. Chernov, Irina A. Rodkina \\ Geological Faculty, Lomonosov Moscow State University, Moscow, Russia \\ Email: irina-rodkina2007@yandex.ru
}

How to cite this paper: Samarin, E. N., Kravchenko, N. S., Zerkal, O. V., Chernov, M. S., \& Rodkina, I. A. (2020). Grouting of Waste of the Baikal Pulp and Paper Mill to Reduce the Technogenic Impact to the Baikal Lake Ecosystem. Journal of Geoscience and Environment Protection, 8, 112-118.

https://doi.org/10.4236/gep.2020.811006

Received: January 16, 2019

Accepted: November 10, 2020

Published: November 13, 2020

Copyright $\odot 2020$ by author(s) and Scientific Research Publishing Inc. This work is licensed under the Creative Commons Attribution International License (CC BY 4.0).

http://creativecommons.org/licenses/by/4.0/ (c) (i) Open Access

\begin{abstract}
Research is devoted to the problem of recycling waste of the Baikal Pulp and Paper Mill, whose activity has caused serious damage to the ecological environment of Lake Baikal and its environs. Grouting waste production is currently the most effective possible decision to the problem of pollutants, such as sludge-lignin and ash, in water objects and groundwater. The results on the grouting of liquid and solid waste from the Baikal Pulp and Paper Mill, represented by sludge lignin and ash, are presented. Cement, liquid glass, colloidal silica, ammonium persulfate, hydrogen peroxide were used as the main hardeners. Samples were formed by mixing the original waste with astringent. The strength in time, shrinkage, resistance to water were studied. Samples formed on the basis of colloidal silica solution have a maximum uniaxial compressive strength of $0.4-0.5 \mathrm{MPa}$, on the basis of liquid glass-0.2 $0.3 \mathrm{MPa}$. Adding fine sand increases the strength by $1.5-1.7$ times. Samples based on ammonium persulfate and hydrogen peroxide do not have sufficient strength. Adding fine quartz sand increases the strength up to 1.0 - 1.2 MPa.
\end{abstract}

\section{Keywords}

Grouting, Sludge-Lignin, Colloidal Silica, Liquid Glass, Pollution of Lake Baikal

\section{Introduction}

Lake Baikal is a unique natural site listed in World Heritage Site (UNESCO) in 1996. This is one of the oldest lakes on the planet and the deepest lake in the world, which contains about 19\% of fresh water. The Baikal Pulp and Paper Mill (BPPM) and its waste, put into operation in 1966, exerted the greatest techno- 
genic load on the ecosystem of Baikal. Baikal pulp and paper mill for more than 40 years of its existence caused significant environmental damage to the environment. One of the manifestations of this damage are landfills for the storage of industrial waste located in the coastal zone of Lake Baikal.

\section{Waste of the Baikal Pulp and Paper Mill}

Technological scheme of the Baikal Pulp and Paper Mill provided for chemical treatment of wastewater, at which sludge is formed-sludge-lignin. At the time of commissioning of the plant, there was no technology for processing ones. In this regard, it was decided to store the sludge-lignin in liquid form in sediment accumulators. These accumulators were commissioned in 1966-1969. A plant was built for the dehydration and incineration of sludge-lignin in 1973. However, the technology for the dehydration of waste was imperfect, and the plant had to be reconstructed. As a result, the newly formed in the process of the Baikal Pulp and Paper Mill sludge-lignin was concentrated to a concentration of $20 \%$ $30 \%$. The resulting concentrate was dried and burned in furnaces specifically designed for this purpose. Sludge lignin from existing drive cards was also attempted to be disposed of in the same way as the newly formed sludge lignin. However, gaseous anaerobic decomposition products were found in the sludge lignin from the sediment accumulators, and the proposed disposal method was considered unsuitable (Shen et al., 2017).

Until the shutdown of the Baikal Pulp and Paper Mill in 2008, the problem of eliminating pulp and paper production was not solved at all. Over the years, the plant has accumulated more than 6.2 million tons of waste stored in the sediment accumulators. For the storage of waste accumulated over the period of operation of the Baikal Pulp and Paper Mill, two Solzansky and Babkhinsky landfills were involved.

For many years, various types of production and consumption wastes from the Baikal Pulp and Paper Mill have accumulated at the Solzansky and Babkhinsky landfills. In addition to lignin sludge dumped at landfills ash and slag from coal combustion, various wastes-solid household, bark-containing and construction waste. Now sludge-lignin, as the main component of waste accumulated in the BPPM, is a multicomponent colloidal system containing a large amount of toxic substances that are both in solid and in dissolved state. The liquid and solid phases are poorly separated.

Combine waste in different storage cards has a very different composition: watered sludge lignin, sludge lignin burning ash, ash and slag from coal burning and contain a large amount of various pollutants (including hydrogen sulfide and formaldehyde) that fall into Baikal with underground and flood waters. The composition of the sludge-lignin is: lignin substances-50\% - 53\%; activated sludge-15\% - 25\%; alumina-5\% - 10\%; polyacrylamide-5\%; cellulose fiber- $5 \%$. The situation is complicated by the high water-holding capacity of waste: the moisture content of sludge-lignin can reach 94\%, ash and slag waste-38\% (Larionova, 2017). 


\section{Methods}

\subsection{Case Study Background}

To solve the problem of recycling the waste of the Baikal Pulp and Paper Mill, in which sludge-lignin predominates, and reduce the level of their environmental hazard, various organizations have proposed to homogenize them. The Irkutsk National Research Technical University, together with the Limnological Institute of the Siberian Branch of the Russian Academy of Sciences and VEB Engineering, proposed a series of recipes characterized by an attempt to use cement and lime as hydraulic binders for curing a mixture of sludge-lignin and ash-slag waste (in various proportions). After hardening, the samples had crush strength up to $1 \mathrm{MPa}$, however, when stored in standing water, they softened significantly.

Joint-stock company Tula NIGP together with the Irkutsk National Research Technical University additionally offered a recipe based on gypsum, nanodispersed silicon dioxide with carbon additives, marble chips and cement. The obtained samples after hardening had a strength of up to $2 \mathrm{MPa}$, but also did not differ in water resistance.

In LLC "STC Technologies XXI", a recipe for grouting of sludge lignin based on a mineral complexing agent with the addition of cement and mineral soil was proposed. The obtained composites had a strength of up to $0.5 \mathrm{MPa}$ in air and $0.3 \mathrm{MPa}$ after water saturation.

Thus, when using the previously proposed formulations, the threshold of "self-supporting strength" (estimated at the level of 5\% - 7\%) is quite successfully overcome for most formulations. However, the obtained composites do not have sufficient water resistance (Timofeeva et al., 2008).

\subsection{Presented Studies}

Since the composition BPPM waste in different sediment accumulators heterogeneous, concreting only lignin slurry is not a complete solution to the problem. Therefore, it is necessary to find a composition of components that is suitable for accumulators containing sludge-lignin and lignin in various proportions with ash and slag waste. It is known that lignosulfonate, which is the main waste of papermaking, hardens under the action of acidic redox hardeners, and the lower the $\mathrm{pH}$, the more durable the polymer is obtained. Of the most well-known variants, sodium dichromate and potassium hexacyanoferrate (III) in combination with hydrogen peroxide were tested. In the first case, the curing hydrolytic sludge-lignin is not observed. In the second case, with the addition of potassium hexacyanoferrate (III) and hydrogen peroxide, a rapid increase in viscosity of the system, subsequent bundle, strong shrinkage, cracking of the composite surface (Rzhanitsyn et al., 1964).

A series of formulations based binders, hardening by different mechanisms, were tested. The main redox hardeners used in this study are colloidal silica solution, liquid glass, ammonium persulfate with hydrogen peroxide. Liquid glass 
(Ministry of Natural Resources and Ecology of the Russian Federation, 2008) and colloidal silica solution (Gallagher et al., 2013; Karol, 2003) were selected as the main components of the formulations, which are widely known in the practice of technical reclamation and form solid complexes during solidification (On the Problem of the Disposal..., 2009). Ammonium persulfate with hydrogen peroxide was chosen as redox-hardeners with a low $\mathrm{pH}$.

The main criterion for evaluating the effectiveness of slam-legnin homonolization was the uniaxial compressive strength of cylindrical samples $4 \mathrm{~cm}$ high and $2 \mathrm{~cm}$ in diameter, which is determined after 7 days of hardening in a humid air environment on the MP-2S device.

\section{Results}

Briefly obtained results can be summarized as follows.

Formulation based on the use of colloidal silica:

1) $70 \%$ lignin $+25 \%$ colloidal silica solution $+5 \%$ hydrogen peroxide.

The gel time of the composite exceeds 30 minutes, which is quite suitable for work on mixing and styling. Sufficiently durable composite, with uniaxial strength is $0.4-0.5 \mathrm{MPa}$. When ash is added in any ratio with sludge-lignin, the viscosity of the reaction mixture increases instantly, and the strength of the composite after hardening decreases sharply.

Formulations based on the use of cement and colloidal silica:

2) $40 \%$ lignin $+40 \%$ ash $+10 \%$ cement $+10 \%$ of colloidal silica-not durable composition, the appearance of cracks on the surface on the second day, due to uniaxial compression was not performed.

3) $30 \%$ lignin $+30 \%$ ash $+7.5 \%$ cement $+7.5 \%$ colloidal silica $+25 \%$ fine quartz sand-the most durable and economically promising recipe using cement. Uniaxial strength is $1.0-1.2 \mathrm{MPa}$.

Formulations based on the use of ammonium persulfate and hydrogen peroxide:

4) $80 \%$ lignin $+7.5 \%$ ammonium persulfate $+12.5 \%$ hydrogen peroxide-the viscosity quickly increases, hardens in 20 minutes, the resulting composite is fragile. Adding colloidal silica solution is not effective. Uniaxial strength is 0.2 $\mathrm{MPa}$.

Liquid glass based formulations:

5) $40 \%$ lignin $+40 \%$ ash $+16 \%$ liquid glass $+1.5 \%$ ammonium persulfate + $2.5 \%$ hydrogen peroxide.

6) $27.5 \%$ lignin $+52.5 \%$ ash $+16 \%$ liquid glass $+1.5 \%$ ammonium persulfate $+2.5 \%$ hydrogen peroxide.

7) $52.5 \%$ lignin $+27.5 \%$ ash $+16 \%$ liquid glass $+1.5 \%$ ammonium persulfate $+2.5 \%$ hydrogen peroxide.

The resulting composite harden in 10 - 20 minutes. In this case, the compressive strength reaches a maximum of $0.2-0.3 \mathrm{MPa}$.

8)-10) The same formulations with addition in proportions of 1:1 with lignin and ashes of fine quartz sand. 
The resulting composite hardens in 15 - 25 minutes. Strength increases 1.5 1.7 times (0.3 - 0.5 MPa).

11) $44.5 \%$ lignin $+44.5 \%$ fine sand $+8.5 \%$ liquid glass $+1 \%$ ammonium persulfate $+1.5 \%$ hydrogen peroxide.

The resulting composite hardens in 20 - 25 minutes. The crushing strength reaches 0.5 - $0.6 \mathrm{MPa}$.

Thus, the results suggest that the addition of the structuring agent (silica sand) positively affects the strength of the final composite.

Formulations that may be recommended for further research:

$80 \%$ lignin $+16 \%$ liquid glass $+2.5 \mathrm{ml}$ of hydrogen peroxide $+1.5 \%$ ammonium persulfate.

$40 \%$ lignin $+40 \%$ ash $+16 \%$ liquid glass $+2.5 \mathrm{ml}$ of hydrogen peroxide + $1.5 \%$ ammonium persulfate.

The strength of the composites reaches $0.6-0.7 \mathrm{MPa}$. Shrinkage in samples with one sludge-lignin is $15 \%$, and in samples containing sludge-lignin and ash in a $1: 1$ ratio- $10 \%$. Cracks on the surface of the composites are not formed. When testing for uniaxial compression, compression of the sample and the formation of cracks are observed only on the lateral surface. After removal of the load, the sample recovers its original form.

\section{Discussion of the Results}

Hydrolyzed lignin is a predominantly linear polymer chain that does not form a three-dimensional structure, which is confirmed by the study of samples under an electron microscope (Figure 1). The addition of liquid glass also does not change the situation-no bulk gel is formed (Figure 2). In this case, only a pseudoglobular structure arises in composites. The final composite can be changed by adding ash, as this results in a structure-forming skeleton of dust particles, but the bulk gel also does not form (Figure 2). This explains the growth of the initial strength of the samples, however, high leaching rates of the

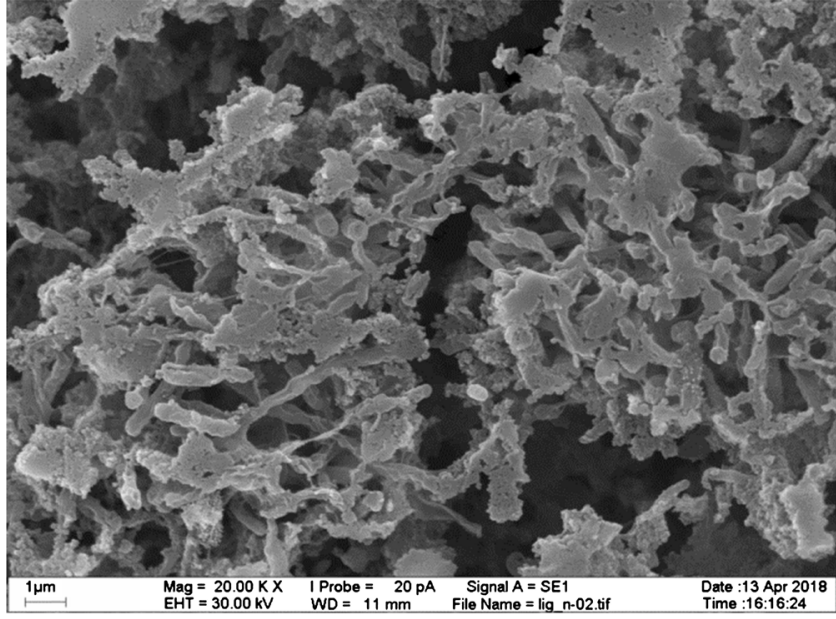

Lignin

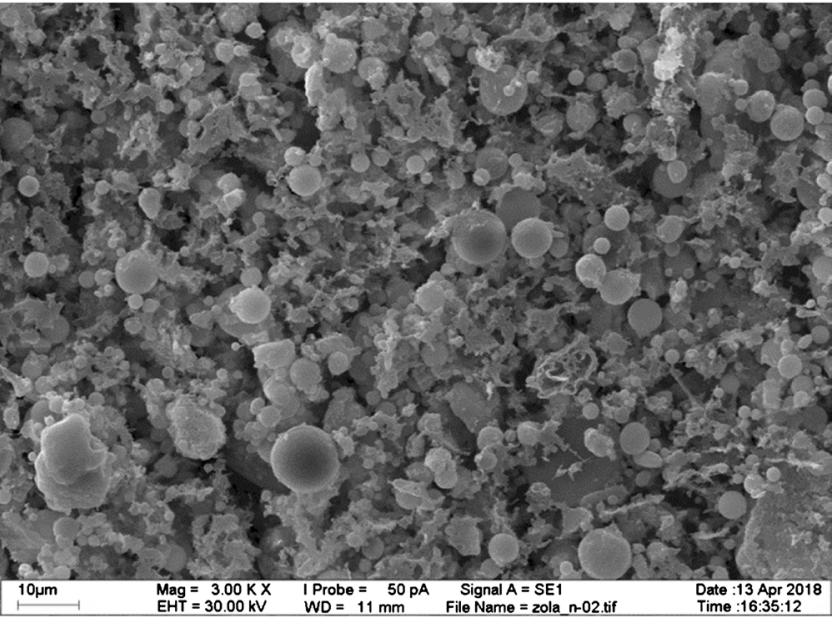

Ash

Figure 1. The SEM image of the original samples. 


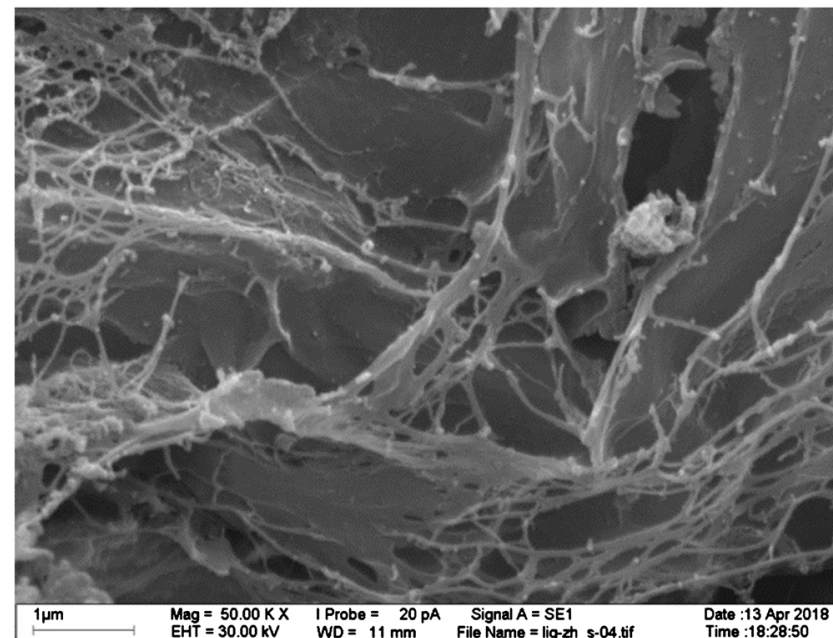

Lignin based

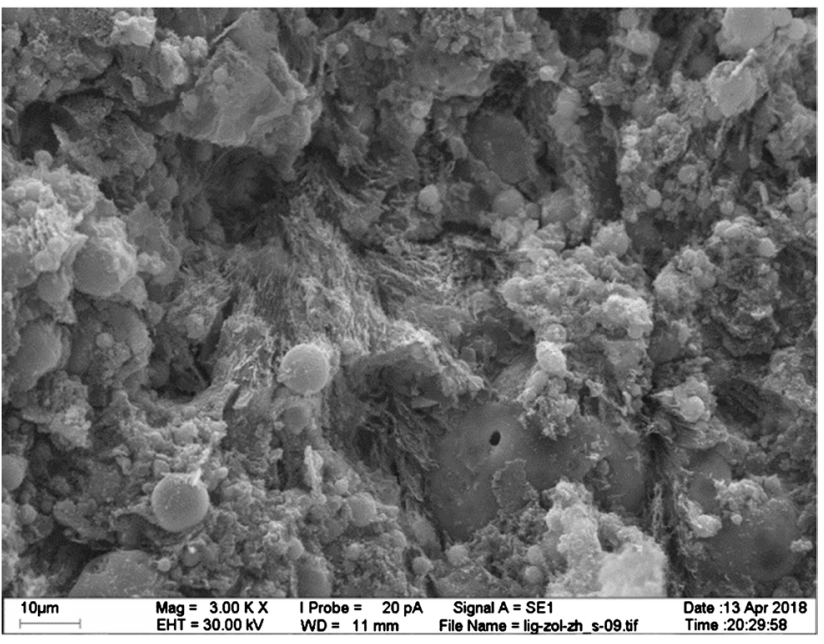

Ash based

Figure 2. The SEM image of composites based on liquid glass.

gel components when interacting even with stagnant water quickly lead to degradation of the entire structure. In addition, the interaction of composites with water (atmospheric, thawed, flood waters) leads to an intensive removal of organic substances, which also complicates the process of grouting.

\section{Conclusion and Possible Solutions to the Problem}

Due to significant humidity, due to partial biodegradation and exposure to precipitation, to reduce the volume and mass of lignin-containing waste, it is advisable to dehydrate them. Since the construction of the mechanical dehydration workshop entails significant economic costs for capital construction and operating costs must be marked dehydration conduct on-site waste disposal. To date, such technologies exist and are used, most often, for dewatering sewage sludge. This technology waste dehydration geosynthetic tubes (closed large-scale geosynthetic membranes), which avoids excessive costs and to improve the environmental situation.

After dehydration, two areas for further problem resolution can be identified.

The first direction. Leave the waste in the tubes, burying them in modernized using modern technologies in the existing maps drives followed overlap on modern technologies, landscaping areas and areas of incorporating into the existing landscape. The second direction. Since lignin thermal conductivity capacity is close to shale and brown coals and has a low ash content, promising it would be to use it as fuel. For example, to produce fuel briquettes mixed with sawdust for heating residential buildings in the region. It is possible to create briquetting production in the shops of the former Baikal pulp and paper mill, thereby creating jobs for the residents of city Baikalsk. That will allow to solve not only environmental and social problems, but will also be very profitable economically. It is likely that the income received from fuel briquettes will largely cover the costs of dehydration and waste briquetting. However, it should be noted that this solution requires additional research. 


\section{Conflicts of Interest}

The authors declare no conflicts of interest regarding the publication of this paper.

\section{References}

Gallagher, P. M., Spatari, S., \& Cucura, J. (2013). Hybrid Life Cycle Assessment Comparison of Colloidal Silica and Cement Grouted Soil Barrier Remediation Technologies. Journal of Hazardous Materials, 250, 421-430. https://doi.org/10.1016/j.jhazmat.2013.01.065

Karol, R. H. (2003). Chemical Grouting and Soil Stabilization. New York-Basel: Marcel Dekker, Inc. https://doi.org/10.1201/9780203911815

Larionova, N. A. (2017). The Use of Industrial Waste as a Secondary Mineral Raw Materials for the Production of Building Materials with Desired Properties. Moscow: GeoInfo.

Ministry of Natural Resources and Ecology of the Russian Federation (2008). On the State of Lake Baikal and Measures for Its Protection in 2009. Irkutsk: Siberian Branch of FGUNPP Rosgeolfond.

On the Problem of the Disposal of Accumulated Waste as a Result of the Activities of the Baikal Pulp and Paper Mill (2009). Session of the Interdepartmental Commission for the Protection of Lake Baikal 05/27/2009. Irkutsk, Russian Federation.

Rzhanitsyn, B. A., Sokolovich, V. E., \& Ibragimov, M. N. (1964). One-Solution Silicatization Method Using Hydrofluoric Acid. In Conference on Soil Consolidation (pp. 40-48). Tbilisi: Georgian Polytechnic Institute.

Shen, P., Hankins, N., \& Jefferis, S. (2017). Selection of Colloidal Silica Grouts with Respect to Gelling and Erosion Behaviour. Geosciences, 7, 6. https://doi.org/10.3390/geosciences7010006

Timofeeva, S. S., Cheremis, N. V., \& Shenkman, B. M. (2008). The Current State of Surface, Groundwater and Wastewater in the Zone of Impact of Sludge Collectors of the Baikal Pulp and Paper Mill. Modern High Technologies, 5, 13-19. 